\title{
O Encontro com a Morte: à Procura do Mestre Quíron na Formação Médica
}

\section{Facing Death: the Search for Quiron in Medical Education}

\author{
Geórgia Sibele Nogueira da Silval \\ José Ricardo de Carvalho Mesquita Ayres ${ }^{I I}$
}

\section{PALAVRAS-CHAVES \\ - Morte. \\ - Educação Médica. \\ - Estudantes de Medicina. \\ - Residentes de Medicina. \\ - Pesquisa Qualitativa.}

\section{KEYWORDS}

- Death.

- Medical Education.

- Medical Students.

- Medical Residents.

- Qualitative Research.

Recebido em: 05/07/2009

Reencaminhado em: 27/01/2010

Aprovado em: 19/02/2010

REVISTA BRASILEIRA DE EDUCAÇ̃̃o MÉDICA

487 34 (4) : 487-496; 2010
${ }^{1}$ Universidade Federal do Rio Grande do Norte, Natal, RN, Brasil.

"Universidade de São Paulo, São Paulo, SP, Brasil.

\section{RESUMO}

Este estudo tem como objetivo compreender como a formação médica lida com o processo de morte de um paciente, e o que os estudantes desejam e sugerem em relação ao tema. Trata-se de estudo qualitativo, baseado na narrativa de estudantes e residentes de Medicina da Universidade Federal do Rio Grande do Norte. A Fenomenologia Existencial, a Hermenêutica Gadameriana e a Teoria da Ação Comunicativa, de Habermas, constituem a base filosófica do trabalho de produção e interpretação das narrativas. Foram combinadas duas estratégias tecno-metodológicas: entrevistas em profundidade e oficinas com utilização de "cenas" projetivas. Os estudantes e residentes transitam entre escassos modelos e poucas experiências pessoais no lidar com a morte de pacientes. O mito de Quíron traduz a procura dos entrevistados por modelos conceituais capazes de ajudá-los a manejar suas vulnerabilidades e desenvolver seus potenciais.

\section{ABSTRACT}

The current study aimed to shed light on how medical education deals with end-of-life issues and death, and on students' related concerns and suggestions. This qualitative study was based on the narratives of medical students and medical residents at the Federal University in Rio Grande do Norte, Brazil. Existential phenomenology, Gadamer's Hermeneutics, and Habermas' Theory of Communicative Action provided the philosophical basis for the narratives' production and interpretation. Two methodological strategies were combined: in-depth interviews and workshops using projective role-playing activities. Students and residents reported a scarcity of models and poor personal experience in coping with the death of patients. The ancient Greek myth of Quiron expresses the participants' search for conceptual models to help them deal with their vulnerabilities and increase their own potential. 
Eu queria não desumanizar, saber cuidar dos meus pacientes na doença e na morte. Como aprendo? Sozinho, no dia a dia?

[Fragmento de entrevista - Rodrigo, residente de medicina, 2005]

\section{INTRODUÇÃO}

Durante a formação médica, estudantes e residentes iniciam o contato com a morte sem subjetividade, sem história. Trata-se do encontro com uma morte "morta", sem alma. Quando, mais tarde, eles se encontram em sua prática com a morte "vivida", onde corpo, alma, alegrias, dores se apresentam de forma intensa, importantes conflitos e paradoxos são experimentados. Eles vão descobrir no encontro com os pacientes que não ser tocado pelo outro e sua dor não será possível o tempo todo. Ao descobrirem isso, reclamam por práticas, professores e política de educação que os auxiliem, que os preparem.

As Diretrizes Curriculares Nacionais do Curso de Graduação em Medicina, homologadas pelo Conselho Nacional de Educação / Câmara de Educação Superior / Resolução CNE/ CES nํ 4, de 7 de novembro de 2001, oficializaram o acompanhamento do processo de morte como uma habilidade a ser desenvolvida no ensino médico.

Lê-se no artigo 5o desse documento: "A formação do médico tem por objetivo dotar o profissional dos conhecimentos requeridos para o exercício das seguintes competências e habilidades específicas", e no seu Item XIII: “atuar na proteção e na promoção da saúde e na prevenção de doenças, bem como no tratamento e reabilitação dos problemas de saúde e acompanhamento do processo de morte ${ }^{1 " \prime}$ (grifo nosso).

A reflexão sobre os diferentes aspectos envolvidos no ensino da morte no âmbito da formação médica e de outros profissionais de saúde tem sido estimulada por diversos autores $^{2-14}$. Contudo, é inegável que as escolas médicas ainda enfrentam dificuldades para assumir o compromisso educacional com essa temática. Poucas oferecem disciplinas que tratem desse assunto $0^{7,8,11,13-15}$ e, quando o fazem, geralmente é apenas na disciplina de Oncologia e/ou Psicologia Médica.

Várias iniciativas estão sendo dirigidas para a educação médica e dos demais profissionais de saúde tendo como horizonte uma atenção menos fragmentada, comprometida com a ética do cuidado ${ }^{15-17,20}$. Isto implica necessariamente o reconhecimento da dimensão do sujeito em cada paciente, e em si mesmo, condição imprescindível a um encontro clínico humanizado no caminho dos futuros médicos. Nesse contexto, se não debruçarmos o olhar sobre o enfrentamento do processo de morte e a educação para tal percurso, não poderemos falar em cuidado integral, em humanização do cuidado.

O contato com o paciente quase morto, ainda sob cuidados médicos, ou até mesmo com os pacientes em seus vários sofrimentos (e não somente com a iminência da morte) poderá impelir o estudante, residente e professor a enxergarem a incompletude de seu saber. Ao reclamar a compreensão da saúde-doença como parte do processo existencial dos pacientes, como de todas as pessoas, a experiência da morte pode favorecer a ressignificação do papel de cuidar, humanizando-o.

Este estudo teve por objetivo conhecer como o manejo da morte é inserido no processo de formação dos médicos, assim como os desejos, dificuldades e sugestões de estudantes e residentes de Medicina em relação a tal aprendizado.

\section{MÉTODO}

Trata-se de uma pesquisa qualitativa com estudantes de Medicina da Universidade Federal do Rio Grande do Norte (UFRN), escolhidos entre todos os períodos de formação (do primeiro ano à residência médica).

A escolha da variação por períodos entre os estudantes atende ao intuito de percorrer várias etapas da formação, a fim de observar possíveis permanências, alterações ou discrepâncias.

As estratégias metodológicas utilizadas para a produção das narrativas foram entrevistas em profundidade com roteiro semiestruturado e oficinas com utilização de "cenas" projetivas, objetivando maior profundidade e segurança na análise interpretativa ${ }^{21-23}$.

A análise de narrativas dos participantes através da cena é um recurso metodológico coconstrutivista que possibilita insights de novos repertórios, a partir de uma experiência antecipada, por meio de dramatizações e visualizações (com relato verbal e escrito posterior à cena).

A seleção das pessoas para participar da pesquisa foi feita por conveniência. O convite aos alunos foi feito, em parte, por intermédio de alguns professores que em sala de aula divulgavam a proposta da pesquisa. Outros convites foram realizados por um contato pessoal da pesquisadora, mas a maior procura dos alunos para a participação veio por meio da divulgação entre eles. Cabe salientar que a pesquisadora responsável pela realização das entrevistas não era docente do curso de Medicina e não tinha nenhum tipo de vínculo com os estudantes e residentes entrevistados.

É interessante registrar que grande parte dos entrevistados (nove) não sabia que a pesquisa abordava também a questão da morte, fato não mencionado pelos autores dos convites (professores e alunos que já haviam feito a entrevista), com 
exceção da própria pesquisadora. $\mathrm{O}$ argumento utilizado foi de que, se os alunos soubessem que abordariam o tema da morte, talvez não tivessem interesse em participar.

As entrevistas ocorreram em uma sessão com duração mínima de uma hora e trinta minutos e no máximo duas horas. As oficinas também ocorreram em uma única sessão, com tempo médio de três horas de duração.

Definimos, para cada ano de curso, pelo menos dois entrevistados (um por período, o que corresponde a dois alunos para cada ano), e dois residentes por ano de residência, dois residentes do primeiro ano (R1) e dois residentes do segundo ano (R2). Garantimos o mínimo de 16 participantes, mas realizamos no final 19 entrevistas (uma a mais no terceiro, quinto e quarto anos). Isto ocorreu em função da procura espontânea dos alunos. Realizamos três oficinas, dividindo os alunos por agrupamento de períodos próximos: Grupo 1: alunos do primeiro, segundo e terceiro anos; Grupo 2: alunos do quinto e sexto anos; e Grupo 3: residentes. Os alunos do quarto ano formariam uma oficina, mas apenas uma aluna compareceu, fato que inviabilizou sua realização, mas, diante do interesse da aluna, realizamos individualmente o trabalho com as "cenas". No total, foram 19 entrevistados (8 homens e 11 mulheres), dos quais dez participaram das oficinas. Apesar de todos terem demonstrado bastante interesse, tivemos dificuldades para conciliar os horários para que todos participassem.

Todas as atividades foram gravadas com a anuência dos entrevistados. Para garantir o caráter sigiloso das informações, os depoimentos foram codificados com nomes fictícios. Cabe ressaltar que no âmbito do recorte desse estudo trabalhamos com a análise das entrevistas.

A interpretação das narrativas foi apoiada em pressupostos e conceitos oriundos da Hermenêutica Filosófica e Teoria da Ação Comunicativa ${ }^{24,25}$.

A dimensão da linguagem, privilegiada na perspectiva habermasiana, é a das relações comunicativas entre os sujeitos, que usam a linguagem para se referir ao mundo e tomar parte dele - ou seja, a dimensão pragmática da linguagem, não o uso das sentenças como uma representação da realidade na nomeação dos objetos e estado de coisas ${ }^{24}$.

O processo interpretativo, por sua vez, obedeceu à regra hermenêutica segundo a qual devemos compreender o todo a partir da parte e a parte com base no todo. Foi operacionalizado por meio de leituras exaustivas e repetidas, que visaram ampliar a unidade do sentido pela concordância de todas as partes singulares com a totalidade compreensiva ${ }^{25}$.

Ainda segundo a hermenêutica, o processo interpretativo-compreensivo dá-se sempre como resposta a uma questão que nos desacomoda em nosso cotidiano, que nos causa estra- nhamento. Em nosso caso, essa pergunta pode ser resumida em: "Como a formação acadêmica pode ajudar estudantes a lidar com o processo de morte de um paciente, o que eles desejam e sugerem neste sentido?"

Este estudo é parte de uma tese de doutorado desenvolvida junto à Faculdade de Medicina da Universidade de São Paulo (2003-2006), com financiamento da Capes, aprovada pela Comissão de Ética para Análise de Projetos de Pesquisa do Hospital das Clínicas da FMUSP — CAPPesq (comissão de ética para análise de projetos de pesquisa do HCFMUSP e da FMUSP), em cumprimento da Resolução nº 196/96 do Conselho Nacional de Saúde. Protocolo 223/05.

\section{RESULTADOS E DISCUSSÃO}

As experiências de ensino-aprendizagem em relação a lidar com o paciente perante a morte são bastante escassas, tanto em virtude da estrutura do curso - que, muitas vezes, não possibilita contato com os pacientes desde o início e apresenta dificuldades de promover um treinamento de habilidades nessa direção - , quanto pelas marcas culturais de negação da morte que caracterizam o homem ocidental ainda neste século.

Nas entrevistas, identificamos que não só o tema morte é evitado, pouco abordado, como também que a experiência do estudante com a morte de um paciente, quando acontece na graduação, ocorre nos últimos anos do curso ou é presenciada de forma acidental. A maioria dos alunos, até a residência, não acompanhou o processo de morte de um paciente. Somente a partir do quinto ano temos relatos de experiências em estágios extracurriculares e curriculares. Ou seja, apenas no internato e na residência surgem as primeiras experiências de fato com a morte de um paciente.

Por outro lado, sabemos que também são raras as oportunidades de conversa entre os alunos e entre eles e os profissionais sobre seus medos, culpas, inseguranças, angústias e outros sentimentos que surgem no cotidiano da relação médico/aluno/paciente e família. Ocorre uma invisibilidade do sofrimento existencial dos estudantes. Há uma falta de acolhimento e continência aos aspectos emocionais dos próprios estudantes, desde as aulas de Anatomia, que podem se reproduzir mais tarde em semelhante falta com seus pacientes.

Millan et al. ${ }^{26}$ afirmam: "a falta de um espaço para a troca de ideias a respeito dessas experiências contribui para acentuar o isolamento, trazendo a crença de que se trata de um problema único que não pode ser compartilhado, pois ninguém mais estaria passando por isso e não compreenderia".

A solidão diante das dificuldades para enfrentar a dor de não salvar, de não saber dar a notícia ruim, de não saber confortar, nem ficar ao lado do paciente à morte, é uma etapa 
vivida que, se não for acolhida, acarreta grande vulnerabilidade ao desenvolvimento de mecanismos rígidos de defesa e de distanciamento do outro e de si mesmo.

Proporcionar uma assistência humanizada na hora da morte (e não apenas nela), como almejam os entrevistados, implica dar lugar à palavra e às suas expressões, dor ou alegria, tanto aos pacientes quanto aos médicos. Implica um processo de aprendizagem que, ao reconhecer a força presente no compartilhar palavras e emoções, caminhe em direção ao desenvolvimento de atitudes que promovam a desejada comunicação qualificada (ou competência comunicacional) e o domínio emocional. É preciso cuidar do processo de cuidar, se entendemos o cuidado como uma atenção à saúde imediatamente interessada no sentido existencial da experiência do adoecimento, físico ou mental, e, por conseguinte, também das práticas de promoção, proteção ou recuperação da saúde ${ }^{27}$ e acompanhamento do processo de morte ${ }^{34}$.

Foi possível nesse estudo observar a procura de modelos por parte dos estudantes e residentes durante a formação médica, seus desejos nesse sentido e as pistas sugeridas por eles. As questões que dispararam tal reflexão foram: Como você acha que a formação acadêmica pode ajudá-lo a lidar com o processo de morte de um paciente? O que você deseja? O que você sugere?

Dividimos as respostas obtidas em cinco eixos analíticos: a) Abordagem do tema morte; b) Experiência prática com pacientes terminais; c) Assistência psicológica; d) Metodologia; e) Professores.

\section{A - Abordagem do Tema Morte}

Os alunos e residentes, tendo já deixado claro que o tema da morte é pouco abordado em sua formação, oferecem sugestões para superar o problema, dentre elas: educação continuada sobre o tema, mais ênfase nas disciplinas humanistas, momentos específicos somados à abordagem continuada.

\section{Educação continuada sobre o tema}

"Eu acredito que principalmente nas disciplinas clínicas, do jeito que há um enfoque da relação médico-paciente, deveria haver também uma reflexão dessas questões sobre a morte, e é uma coisa que não tem até o momento. Deveria ser abordado de forma mais cotidiana, já que vai fazer parte da vida do profissional médico, então tem que começar a fazer parte da vivência do estudante ao longo do curso" [fragmento de entrevista - Tibério $-3^{\circ}$ ano $/ 5^{\circ}$ período]

"Tem que primeiro falar sobre a morte, que não se fala, $e$, assim, tentar realmente fazer com que fosse uma coi- sa durante o curso inteiro e não só uma coisa pontual, que fosse em etapas, ou pelo menos de mês em mês; eu não sei de que forma se iria abordar isso, mas que fosse uma coisa mais seguida, pra gente também ter esse segmento pra gente." [fragmento de entrevista - Simone $-6^{\circ}$ ano $/ 12^{\circ}$ período]

Falar sobre a morte durante o curso, fazer parte da agenda acadêmica é o solicitado. Alguns pesquisadores vêm advogando que a educação formal sobre a morte e o morrer pode diminuir a dificuldade de tratar do assunto com pacientes terminais $6,11,13,19$.

Apesar de crescentes iniciativas a esse respeito, Eizirik ${ }^{19}$ cita dados apresentados por Foley, estimando que apenas cinco das 126 faculdades de Medicina dos Estados Unidos possuem um curso específico voltado ao cuidado do paciente terminal, assim como somente $26 \%$ dos 7.048 programas de residência médica oferecem um curso a respeito dos aspectos médico-legais no cuidado desse tipo de paciente ${ }^{29}$.

Klafke $^{5}$ sugere que essa dificuldade decorre da falta de preparo desses profissionais, além do comportamento apresentado pelos pacientes durante a evolução de uma doença terminal.

\section{Maior ênfase do tema na disciplina de Psicologia Médica}

A disciplina foi lembrada como espaço que, embora traga o tema, o faz de forma superficial e abordando apenas parte da relação médico-paciente perante a morte.

\footnotetext{
“Não sei, já que a gente paga uma cadeira de Psicologia Médica, ela poderia abordar melhor esse assunto. Com alguma prática, ou mais exemplos de como lidar, falas do médico, não só do que passa o paciente." [fragmento de entrevista - Cecília $-5^{\circ}$ ano $/ 10^{\circ}$ período]
}

\section{Momento específico para abordagem do tema somado à abordagem continuada}

Alguns alunos sugerem que se construa uma disciplina ou projeto de extensão para se trabalhar apenas a relação do médico com a morte, ainda que o tema perpasse as clínicas.

"[...] no currículo poderia ter um dia na semana, uma manhã,
uma tarde, um turno todo, pra gente fazer algumas dinâmi-
cas de grupo, dividir a turma em vários grupos e cada um ia
discutir um tema sobre a morte; ou fazer um horário mais
light, pra justamente conversar essas coisas do médico com
o paciente terminal. Pode ser uma disciplina, uma extensão.
A gente poderia até tentar montar um grupo, eu não
sei como é que a gente faria isso dentro da univer- 
sidade, mas eu acho que tem como, a gente poderia tentar montar um grupo, por exemplo, de estudantes de Medicina e de psicólogos." [fragmento de entrevista - Felipe $-4^{\circ}$ ano $/ 8^{\circ}$ período]

A fala do estudante nos remete à experiência de grupos de reflexão que vêm se difundindo em algumas universidades brasileiras, por meio de disciplinas humanísticas onde ocorrem as discussões entre pequenos grupos de estudantes da mesma fase do curso ${ }^{16}$; programas de tutorias, por exemplo, da FMUSP ${ }^{30}$, onde se reúnem estudantes de vários anos e um professor tutor; ou ainda professores de várias clínicas com alunos do mesmo período, por exemplo, na disciplina eletiva "Reflexão sobre a Prática Médica/Faculdade de Medicina da UFRJ"31.

Cabe registrar que as iniciativas com alunos do quinto ou sexto ano são as que mais têm se difundido. Dentre elas, citamos as sessões de sociodrama na Faculdade de Medicina de Botucatu (FMB), dirigidas ao sexto ano $^{32}$.

Os grupos de reflexão, ao debaterem as vulnerabilidades pessoais e profissionais e as limitações da prática médica, ao mesmo tempo em que acatam a sensibilidade como uma dimensão do humano que pode ser utilizada a serviço do saber-fazer médico, ao contrário de representarem um ruído à sua prática, também podem constituir um espaço de cuidado do sofrimento dos profissionais da medicina. São estratégias herdeiras dos grupos Balint, que consistem na formação de grupos de reflexão sobre a tarefa médica, coordenados por um profissional da área psi e destinados a clínicos e/ou especialistas centrados na discussão de casos com abordagem de aspectos pessoais, familiares e institucionais ${ }^{33}$.

\section{B - Experiência prática com pacientes terminais}

Ao longo da pesquisa, os entrevistados avaliaram sua experiência prática como escassa e dificultada pela existência de um número grande de alunos nesses momentos. Solicitam mais experiência com o paciente terminal, mediante acompanhamento, preparo e supervisão de médicos e profissionais de saúde mental — psiquiatras e/ou psicólogos.

Vejamos exemplos:

“Uma sugestão, já dada a um professor nosso, é fazer escala em UTI. Numa das aulas, ele perguntou se algum dos estudantes já tinha visto alguém morrer; ninguém respondeu, até porque acho que ninguém realmente viu. Então, colocar o estudante de Medicina frente a frente com o paciente terminal, em estado muito grave, acompanhar aquele paciente e, infelizmente se acontecer o óbito, se ele estivesse lá pra acompanhar e pra aprender a lidar com isso, seria importante. Antes teria que preparar o aluno. Jogar o aluno numa UTI com paciente grave, mesmo acompanhado de um médico docente, já seria uma parte final desse aprendizado." [fragmento de entrevista - Tibério - 3o ano / 5o período]

"Eu acho que ajudaria ter prática, acompanhar. A gente tem prática na maternidade, com bebê, adultos, por que não ter com o paciente terminal?" [fragmento de entrevista Fernanda $-4^{\circ}$ ano / $8^{o}$ período]

Já Ramos-Cerqueira et al. ${ }^{32}$ comentam:

Inegavelmente a existência do internato foi um avanço, na medida em que determinou um período mínimo de atividade prática intensa e supervisionada. Contudo, essa vivência intensiva acabou por levar o aluno a deparar-se, súbita e cotidianamente, com situações difíceis: o seu próprio limite, os limites de seu paciente e os limites da medicina. Muitas vezes ainda não viveram, de forma gradual, outras situações de encontro com o paciente, com a comunidade e com o sistema de saúde, já entrando em contato com atendimento hospitalar terciário e quaternário.

O contato com o paciente terminal pode diminuir o medo de interagir com tais pacientes ${ }^{3,5}$, mas é imprescindível um preparo adequado para essa experiência.

Outra sugestão mencionada diz respeito a consultas conjuntas, como demonstra o seguinte fragmento:

"Felipe: Uma ideia que eu já tive foi a seguinte: enquanto estudante, a gente não acompanha médicos?

Entrevistadora: Exato.

Felipe: Pra desenvolver o lado técnico, às vezes eu vou pra cirurgia com um médico, a gente discute o caso; por que a gente não pode, por exemplo, acompanhar um psicólogo hospitalar? Assim, não que a gente esteja querendo invadir a área de vocês, mas pra gente ir tendo uma noção de como lidar com essas coisas. A gente poderia fazer isso, vamos supor, um curso de extensão com os docentes sendo alguns psicólogos, e vamos então pra Liga, pro hospital Luiz Antonio. [referindo-se a um hospital referência em oncologia]." [fragmento de entrevista - Felipe, $4^{\circ}$ ano / $8^{\circ}$ período]

A consulta conjunta é uma prática de ensino em serviço, originária da interconsulta, que visa integrar pessoas e saberes no cotidiano dos serviços de saúde, objetivando sensibilizar, mobilizar e capacitar para mudar concepções, práticas e relações, a fim de proporcionar cuidado integral à saúde. 
O conceito de interconsulta foi divulgado por Ferrari et al. ${ }^{35}$. Os autores advogam o emprego dessa técnica para substituir a prática de respostas a pedidos de parecer de um hospital de Psiquiatria - o Hospício de Las Mercedes, em Buenos Aires. Segundo os autores, a técnica da interconsulta dinamiza a prática individual de respostas de pareceres, transformando-a num momento interativo, de discussão dos elementos envolvidos no atendimento. O emprego dessa técnica fertilizou e renovou o trabalho de psiquiatria conhecido também como ligação.

A consulta conjunta vem sendo exercitada nos ambulatórios do Hospital Universitário Pedro Ernesto, da Universidade do Estado do Rio de Janeiro (Hupe/Uerj), com o propósito de capacitar médicos e psicólogos para a prática do cuidado integral à saúde ${ }^{33}$. No entanto, não era do conhecimento de nosso entrevistado, e sua sugestão surge da necessidade vivenciada de integrar esses domínios.

\section{C - Assistência Psicológica}

A proposta de serviços de assistência psicológica surge entre alguns alunos, especialmente os do internato (quinto e sexto anos). Quando o estudante não consegue elaborar os conflitos gerados pelas dificuldades próprias do curso médico, é importante que existam propostas de assistência psicológica e acompanhamento psicopedagógico, fazendo parte de um programa de atenção primária à saúde dos estudantes ${ }^{36,37}$. Os estudantes ilustram tal argumentação:

\begin{abstract}
"Eu acho que tem que ter um suporte psicológico, porque teve uma amiga minha que, antes mesmo de entrar na faculdade, já acompanhava com a psicóloga semanalmente, [...] outra colega da minha turma é acompanhada por psicólogo e psiquiatra. A gente tem que estudar muito, responsabilidade enorme, a gente lida todo dia com choro, com sofrimento, de pacientes com dor na unha a casos mais complicados, abrange todo mundo, mas muitos de nós entramos muito jovens, então fica mais difícil ainda lidar com isso." [fragmento de entrevista - Carmen $-5^{\circ}$ ano $/ 9^{\circ}$ período]
\end{abstract}

Millan et al. ${ }^{26}$, em levantamento realizado sobre esse tipo de serviço, encontram que a assistência psicológica ao aluno de Medicina no Brasil remonta à década de 1950, mas poucos serviços conseguiram dar continuidade ao trabalho por um período longo, apesar de haver consenso quanto à importância e necessidade deles. Esses autores afirmam que "a escassez de recursos materiais, a política institucional e a indefinição de um setting adequado parecem ser as causas mais comuns que levam à extinção dos serviços"26.

\section{D - Metodologia}

Explorar o autoconhecimento e antecipar situações que auxiliem na expressão dos afetos experimentados pelos alunos fazem parte do repertório de objetivos que norteiam as metodologias ativas, não apenas a Aprendizagem Baseada em Problemas (ABP) como um todo, mas a utilização de grupos de reflexão e consulta conjunta, por exemplo.

Os entrevistados têm clareza de que, diante da proximidade da morte de seus pacientes, necessitam desenvolver atitudes que os ajudem nesse enfrentamento. Assim, sugerem esse tipo de recurso, conforme sintetiza o discurso da aluna:

"Primeiro, discutir o tema que não é discutido, discutir
de forma prática, seja com filmes, teatros, psicodra-
mas, as situações vividas por cada um, a realidade ser dis-
cutida porque aí é que a gente mostra crescimento, e tudo ser
discutido em grupo porque a experiência de um pode ajudar
muito do ponto de vista geral." [fragmento de entrevista
- Simone - $6^{\circ}$ ano / 12 - período]

Poder falar em morte é preciso, como é preciso aprender a manejar as dificuldades compartilhando com os pares, como ilustra a seguinte fala:

"Eu não sei qual o intuito do psicodrama, mas serviu pra
isso, porque a gente montava entre a gente quem era o médi-
co, quem era o paciente, depois você tinha que contar pro pa-
ciente o diagnóstico; foi bem interessante, isso seria de grande
utilidade pra gente não ser pego de surpresa, porque eu não
fui pega de surpresa no Giselda [hospital de doenças infecto-
contagiosas], mas você pode ser pega de surpresa quando um
professor chega e diz: 'vamos atender um paciente e você vai
dar o diagnóstico pra ele'. A gente também aprende com o
modelo que o outro representou. [fragmento de entre-
vista - Cecília - $5^{\circ}$ ano $/ 10^{\circ}$ período]

Os métodos psicodramáticos, como a utilização de cinema, são recursos que ajudam na projeção e expressão dos sentimentos, como na identificação com os papéis, de pacientes ou médicos, ajudando na construção da identidade médica, assim como as experiências de consulta conjunta, grupos de reflexão e, mais recentemente, a medicina narrativa.

O cinema aumenta as possibilidades do concreto e das vivências que em cada pessoa se encontram reduzidas a um pequeno repertório de experiências pessoais ${ }^{38}$. Ele contribui para uma reflexão acerca de valor, atitudes, limitações e modos de ser do humano.

A medicina narrativa, por sua vez, contribui para desenvolver competências em comunicação e ajuda o estudante a 
aprofundar seus sentimentos e dificuldades com os pacientes. Foi proposta por Rita Charon ${ }^{39}$, como um modelo para o desenvolvimento de uma prática médica humana e efetiva. Essa autora criou o termo "medicina narrativa" para designar uma medicina praticada com competência narrativa e marcada por uma compreensão de situações narrativas complexas entre médicos, pacientes, colegas e o público.

Segundo Almeida et al. ${ }^{40}$, foi implantada inicialmente na Universidade de Colúmbia, em Nova York. Os treinamentos estimulam os estudantes a escrever sobre seus pacientes em linguagem não técnica, ajudando-os a descobrir e a compreender seus próprios sentimentos e o saber dos pacientes. Esse programa fornece um treinamento em leitura de textos literários, para ajudá-los a interpretar e compreender o sentido das histórias de outros. O conhecimento de obras destacadas da literatura pode ajudar o futuro médico a conhecer a si mesmo e aos pacientes, potencializando sua habilidade empática. No Rio de Janeiro, na Escola Superior de Ciências de Saúde da Fundação de Ensino e Pesquisa em Ciências da Saúde (ESCS), a medicina narrativa vem sendo utilizada na terceira série do curso de Medicina.

Selecionamos algumas reflexões no debate realizado nas oficinas, em que se sugeriu a utilização das "cenas" como um recurso capaz de auxiliar os estudantes durante a formação para lidar com a morte:

\footnotetext{
"A ideia da oficina é bem interessante, porque na oficina, principalmente quando tem essa parte expressiva de arte, é que às vezes a gente consegue. É nessas horas, do cinema, de uma dinâmica, de um colega contando um caso, que a pessoa consegue se abrir. Como foi agora ao construir essas "cenas", eu parei para pensar mesmo como seria, me emocionei e agora na discussão tive outras ideias, foi muito reconfortante ver como a gente faria, é meio ensaio, né?" [fragmento da oficina - Cecília $-5^{\circ}$ ano / $10^{\circ}$ período]

"Teve momentos difíceis aqui para escrever essas "cenas", mas também foi o melhor de ter participado dessa pesquisa, saio daqui querendo mais momentos desses, acho que cresci. Tem como pensar isso numa disciplina que falasse de morte, de relação médico-paciente?" [fragmento da oficina - Rafael 5o ano / $10^{\circ}$ período]
}

Interessante observar que, na confecção das "cenas", as narrativas construídas ajudaram o autoconhecimento dos participantes. Ao criarem os roteiros, suas "obras de arte" projetavam seus próprios medos, dúvidas. Embora antecipassem também possíveis sentimentos dos pacientes, o foco maior era o médico — portanto, eles. Pensar, compartilhar, representou um início de uma atenção humanizada, do cuidado com esses cuidadores que trilham seu caminho entre os modelos de ser médico que negam ou acolhem a dor, a morte.

Diante da necessidade de discutir o tema da morte nas escolas médicas, várias propostas de criação de cursos para educadores vêm surgindo, sempre conduzidas por estratégias como cinema, psicodrama, role-playing, workshops - todas buscando retirar a impessoalidade do tema, desenvolver competências comunicativas e encorajar o lidar com os próprios sentimentos $^{40-46}$.

\section{E - Modelos potenciais: os professores}

\begin{abstract}
"Na verdade, quando o professor sabe lidar com o paciente à morte, ele sabe ensinar também. Não adianta mudar só o currículo, tem que mudar a mentalidade." [fragmento de entrevista - Carmen $-5^{\circ}$ ano / $9^{\circ}$ período]

"O contato dos internos é mais com a gente, e se a gente não aprendeu a lidar com o paciente terminal, como é que fica? Eu tento passar o que eu acho, mas é preciso investir no professor desde o início para que ele trate dessa questão." [fragmento de entrevista — Rafael, residente 2]
\end{abstract}

A necessidade de um modelo identificatório parece ser proporcional à constatação do despreparo de partes dos professores para exercer esse lugar no lidar com a morte. Segundo os depoimentos, é preciso resgatar a relação professor-aluno. Nas palavras de uma aluna, "mudar a mentalidade", e no dizer de Arruda, "reumanizar o professor"47.

Quanto à formação da identidade médica, cabe lembrar que o estudante de Medicina se encontra numa etapa evolutiva específica (adolescente - adulto jovem). É uma importante fase de individuação que tem entre suas características esse movimento de abandonar posturas e atitudes anteriores e adquirir nova identidade pessoal e médica, momento em que estará particularmente sensível à influência de seus pares colegas e, especialmente, professores ${ }^{7,8}$.

Postulam-se, então, como metas para a composição do ensino médico, medidas que permitam a identificação do estudante com profissionais claramente capazes de expressar e discutir seus sentimentos frente às situações de dor, sofrimento e morte. Sobretudo, buscam-se professores e preceptores mais simpáticos com seus pacientes, hábeis no sentir e em verbalizar suas experiências com as sensações geradas corriqueiramente, oferecendo ao acadêmico uma vivência mais saudável, mesmo que ainda ansiogênica. É primordial que haja acesso do acadêmico à convivência direta com médicos 
ou preceptores do próprio curso, para possibilitar a formação de um modelo identificatório, uma vez que somente o contato com a hierarquia do hospital-escola não é capaz de estabelecê-lo de forma adequada, na maior parte das vezes ${ }^{40}$.

Nessa mesma direção, Rocco ${ }^{49}$ alerta que estes podem ser bons ou maus modelos para o estudante, dependendo da forma como propiciam o contato com a motivação humana da profissão.

\section{CONSIDERAÇÕES FINAIS}

Apesar da presença do discurso de reumanização do processo de morte de um paciente, a fala dos entrevistados atesta que a prática dessas interações é dificultada pelo pouco suporte de ensino-aprendizagem nessa direção, aliado à falta de acolhimento e continência aos aspectos emocionais dos próprios estudantes, que mais tarde poderão reproduzir essa mesma falta com seus pacientes.

O mestre Quíron é o ideal desejado por eles exatamente por saber lidar com o próprio sofrimento e o do outro, conseguindo estar ao lado de seus discípulos e pacientes no adoecimento e na morte.

Quíron era um centauro, meio homem e meio cavalo, grande sábio e amigo dos mortais. Por seu intermédio, os conhecimentos médicos foram divulgados aos mortais. Também ensinava música e moral. Era conhecido por ser um educador bondoso e capaz de desenvolver as potencialidades de seus discípulos. Foi educador de vários heróis, dentre os quais aquele a quem mais se afeiçoou - Asclépio. Quíron foi atingido acidentalmente por uma flecha de Heracles e sofria de dores terríveis que seus conhecimentos médicos não eram capazes de mitigar. Conviver com suas próprias dores talvez tenha lhe ensinado a conviver com a dor do outro e a lidar com os limites, com a mortalidade.

O mito de Quíron traduz a procura dos estudantes e residentes entrevistados que reclamam a existência de modelos potenciais com os quais possam se identificar e sejam capazes de ajudá-los a desenvolver suas potencialidades.

A dificuldade de inclusão do preparo para lidar com a morte na formação acadêmica não é apenas um efeito acidental do ensino médico. Implica questões epistemológicas que estão na base da própria racionalidade da biomedicina, que, no dizer de Canguilhem ${ }^{50}$, é a dificuldade de apreender a lidar com a dor, o sofrimento e a morte.

É fato que as defesas implementadas para o afastamento do outro e dos próprios sofrimentos operam no corpo da linguagem, bem como na possibilidade de aprender a lidar com a proximidade da dor do outro. É no terreno da intersubjetividade, no poder falar algo com alguém, que acontecem os encontros ou desencontros da relação do médico com seu paciente à morte, abrindo-se possibilidades de um lidar frágil e limitado por um monólogo tecnicista, ou de um rico aprendizado na direção da humanização do cuidado.

A trajetória nessa direção cuidadora exige tempo, poder, ideais individuais, coletivos e políticos, cuja urgência não permite esperar por mudanças estruturais profundas (embora precise delas). Mas também é fato que algumas mudanças estão sendo ensaiadas nas várias iniciativas apontadas neste trabalho.

Aprender com Quíron a lidar com a morte sem perder a humanidade pode significar transformar o encontro médico-paciente, professor-aluno, em momentos dialógicos, em verdadeiros encontros; pode ensinar a aprender a cuidar do cuidado de todos os sujeitos envolvidos no saber-fazer em medicina.

\section{REFERÊNCIAS}

1. Brasil. Ministério da Educação. Conselho Nacional de Educação. Diretrizes Curriculares Nacionais do curso de graduação em Medicina. [online]. [acesso em 12 mar. 2005]. Disponível em: http://www.abem educmed.org. br/cne_minuta_resolucao.htm

2. Concone MH. O vestibular da anatomia. In: Martins JC. A morte e os mortos na sociedade brasileira. São Paulo: Hucitec; 1983.

3. Howells K, Gould M, Fields D. Fear of death and dying in medical students: effects of clinical experience. Med Educ. 1986;20(6):502-6.

4. Boemer M. A morte e o morrer. $2^{\underline{a}}$ ed. São Paulo: Cortez; 1989.

5. Klafke TE. O médico lidando com a morte: aspectos da relação médico-paciente terminal em cancerologia. In: Cassorla RMS. Da morte: estudos brasileiros. Campinas: Papirus;1999. p.25-49.

6. Rappaport W, Witzke D. Education about death and dying during the clinical years of medical school. Surgery.1993;113(2):163-5.

7. Zaidhaft S. Morte e formação médica. Rio de Janeiro: Francisco Alves; 1990.

8. Viana A, Piccelli H. O estudante, o médico e o professor de medicina perante a morte e o paciente terminal. Rev Assoc Med Bras.1998;44(1):21-7.

9. Rosa CAP. A morte e o ensino médico. Rev Bras Educ Méd. Rio de Janeiro1999;23(2/3):52-67.

10. Lino GGS. A morte e o estudante de medicina: contemplam-se, mas não se conhecem. Rio de Janeiro; 2003. Mestrado [Dissertação] — Universidade Federal do Rio de Janeiro. 
11. Kovács MJ. Educação para Morte: temas e reflexões. São Paulo: Casa do Psicólogo; 2003.

12. Falcão EBM, Mendonça SB. Formação médica, ciência e atendimento ao paciente que morre: uma herança em questão. Rev Bras Educ Méd. 2009;33(3):364-73.

13. Marta GN, Marta SN, Filho AA Job JRPP. O estudante de Medicina e o médico recém-formado frente à morte e o morrer. Rev Bras Educ Méd. 2009; 33(3):405-416.

14. Sadala MLA, Silva MP. Cuidar de pacientes em fase terminal: a experiência de alunos de medicina. Interface Comun Saúde Educ. 2008;24(12):7-21.

15. Souza AN. Formação médica racionalidade e experiência. Ciênc Saude Colet. 2001;6(1):87-96.

16. De Marco MA, org. A face humana da medicina: do modelo biomédico ao modelo biopsicossocial. São Paulo: Casa do Psicólogo; 2003.

17. Ramos-Cerqueira A TA, Lima MCP, Torres AR, Reis JRT, Fonseca NMV. Era uma vez... contos de fadas e psicodrama auxiliando alunos na conclusão do curso médico. Interface Comun Saúde Educ. 2004-2005;9(16)81-9.

18. Falcão EBM, Lino GGS. O paciente morre: eis a questão. Rev Bras Educ Méd. 2004;28(2):106-18.

19. Eizirik C, Polanczyk GV, Eizirik M. O médico, o estudante de medicina e a morte. Rev AMRIGS. 2000;44(1/2):50-5.

20. Rios IC, Junior AL, Kaufman A, Vieira JE, Scanavino MT, Oliveira RA. A integração das disciplinas de humanidades médicas na faculdade de medicina da USP: um caminho para o ensino. Rev Bras Educ Méd. 2008;32(1):112-21.

21. Kvale S. Interviews: an introduction to qualitative research interviewing. Thousand Oaks:Sage publications;1996.

22. Minayo MC. Hermenêutica e Dialética como caminho do pensamento Social. In: Deslandes SF. Caminhos do pensamento: epistemologia e método. Rio de Janeiro: Ed. Fiocruz; 2002. p.83-108.

23. Paiva V. Analysing sexual esperiences through scenes: a framework for sexualty education and evaluation. London: Sex Educ. 2005;5(4):345-59.

24. Aragão L. Habermas: filósofo e sociólogo do nosso tempo. Rio de Janeiro:Tempo brasileiro; 2002.

25. Gadamer HG. Verdade e Método II: Complementos e índice. Petrópolis: Vozes; 2002.

26. Millan LR, De Marco OLN, Rossi E, Millan MPB, Arruda PCV. Alguns aspectos psicológicos ligados à formação médica.Cap. 4. O universo psicológico do futuro médico. São Paulo: Casa do Psicólogo; 1999. p.75-82.

27. Ayres JRCM. O cuidado e os modos de ser (do) humano e as práticas em Saúde. Saúde Soc. 2004;3(3):16-29.
28. Barton D. The need of including instruction on death and dying in the medical curriculum. J Med Educ. 1972;47(3):169-75.

29. Foley K. Competent care for the dying instead of phisician-assisted suicide. N Engl J Med. 1997; 336:54-8.

30. Bellodi PL, Marinho T, Massaroppe B, Martins MA, Santos MAS. Temas para um programa de tutoria em Medicina: uma investigação das necessidade dos alunos da FMUSP. Rev. Bras. Educ Méd. 2004;28(2):119 -27.

31. Souza NA. Formação médica, racionalidade e experiência. Ciênc Saude Colet.. 2001;6(1)87-96.

32. Ramos-Cerqueira ATA, Lima MCP. A formação da identidade do médico: implicações para o ensino de graduação em medicina. Interface Comun Saúde Educ. 2002;6(11):10716

33. Mello Filho J, Silveira LMC. Consulta conjunta: uma estratégia de capacitação para a atenção integral à saúde. Rev Bras Educ Méd. 2005;29(2):147-51.

34. Silva GSN. A construção do 'ser médico' e a morte: significados e implicações para a humanização do cuidado. São Paulo;2006. Doutorado [Tese] — Universidade de São Paulo.

35. Ferrari H, Luchina IL, Luchina N. La Interconsulta Médico-Psicologica en el Marco Hospitalario. Buenos Aires: Nueva Visión;1971.

36. Pereira AMA, Costa LSM. O abuso como causa evitável de estresse entre estudantes de Medicina. Rev Bras Educ Méd. 2005;29(3):185-90.

37. Rezende CHA, Abrão CB, Coelho EP, Passos LBS. Prevalência de sintomas depressivos entre estudantes de medicina da Universidade Federal de Uberlândia. Rev Bras Educ Méd. 2008; 32(3):315-323.

38. Blasco GP. Medicina de Família \& Cinema: Recursos Humanísticos na Educação Médica. São Paulo: Casa do Psicólogo; 2000.

39. Charon R. Narrative Medicine: form, function, and ethics. Ann Intern Med. 2001;134(1):83-7.

40. Almeida HO, Alves NM, Costa MP, Trindade EMV, Muza GM. Desenvolvendo Competências em Comunicação: Uma Experiência com a Medicina Narrativa. Rev Bras Educ Med.2005;29(3):208-216.

41. Atting T. Person centred death education. Death Stud.1992;16(4):357-70.

42. Coffman VT, Coffman SL. Behavioral rehearsal: a way of talking about the dying process. Omega. 1995-1996; 32(1):63-76.

43. Kovács MJ. Implantação de um serviço de plantão psicológico em unidades de cuidados paliativos. Rev Bras Med.1999;56(8):786-94. 
44. Turini B, Martins Neto D, Tavares MS, Nunes SOV, Silva VLM, Thomson Z. Comunicação no ensino médico: estruturação, experiência e desafios em novos currículos médicos. Rev Bras Educ Méd. 2008; 32(2):264-70.

45. Brown RF, Bylund CL. Communication skills training: describing a new conceptual model. Acad Med 2008;83(1):3744.

46. Nunes SOV, Vargas HO, Liboni M, Martins Neto D, Turini B. O ensino da psiquiatria, habilidades de comunicação e atitudes no currículo integrado do curso de medicina da Universidade Estadual de Londrina. Rev Bras Educ Méd. 2008; 32(2):210-16.

47. Arruda, PCV. As relações entre alunos, professores e pacientes. In: Millan LR, De Marco OLN, Rossi E, Millan MPB, Arruda PCV. O Universo Psicológico do futuro médico: vocação, vicissitudes e perspectivas. São Paulo: Casa do Psicólogo; 1999. p.43-73.

48. Castro, FC. Os temores na Formação e Prática da Medicina: Aspectos Psicológicos. Rev Bras Educ Med. 2004;28(1):38-45.

49. Rocco RP. Relação estudante de medicina-paciente. In: Mello Filho J. Psicossomática Hoje. Porto Alegre: Artes médicas; 1992. p.45-56.
50. Canguilhem G. O normal e o patológico. $3^{\text {o }}$ ed. Rio de janeiro: Forense Universitária;1977.

\section{CONTRIBUIÇÃO DOS AUTORES}

Geórgia Sibele Nogueira da Silva elaborou e desenvolveu o estudo original e escreveu o artigo. José Ricardo Carvalho de Mesquita Ayres orientou a elaboração e o desenvolvimento do estudo e participou da redação.

\section{CONFLITO DE INTERESSE}

Declarou não haver.

\section{ENDEREÇO PARA CORRESPONDÊNCIA}

Geórgia Sibele Nogueira da Silva

Departamento de Psicologia - UFRN

Campus Universitário - Lagoa Nova — Natal

CEP. 59078-970 RN

E-mail: gsibele@uol.com.br 